Original Research Article

\title{
Clinical profile of HIV positive patients attending ART centre of a tertiary care hospital
}

\author{
Tejas M. Doshi ${ }^{1 *}$, Rusva A. Mistry ${ }^{2}$, Manish N. Mehta ${ }^{1}$
}

${ }^{1}$ Department of Medicine, Guru Gobind Government Hospital, Jamnagar, Gujarat, India ${ }^{2}$ Department of Pharmacology, $5^{\text {th }}$ floor, M.P. Shah Government Medical College new building, Jamnagar, Gujarat, India

Received: 16 May 2018

Accepted: 26 June 2018

*Correspondence to: Dr. Tejas M. Doshi, Email: tejas_m_doshi@ gmail.com

Copyright: (C) the author(s), publisher and licensee Medip Academy. This is an openaccess article distributed under the terms of the Creative Commons Attribution NonCommercial License, which permits unrestricted noncommercial use, distribution, and reproduction in any medium, provided the original work is properly cited.

\begin{abstract}
Background: HIV infection/AIDS is a global pandemic greatly exceeds earlier prediction. With widespread availability and uses of Anti Retroviral Therapy (ART), HIV becomes a chronic manageable illness but immediate and long term side effects become a major problem. The objective of the study was to study clinical profile of HIV positive patients attending A.R.T. centre of a tertiary care hospital.
\end{abstract}

Methods: Observational and prospective study was carried out over $100 \mathrm{HIV}$ positive Patients attending ART centre of G.G.G Hospital, Jamnagar, Saurastra, Gujarat over a period of 12 months.

Results: Out of $100 \mathrm{HIV}$ positive studied patients, maximum cases $(95 \%)$ were in the age group of 15-49 years, $75 \%$ were males. (58\%) cases were from rural area and (56\%) were illiterate. Maximum cases were having sexual (79\%) route of transmission. Most common symptom among HIV positive patients was weight loss $(62 \%)$ followed by fever $(58 \%)$. Mycobacterium tuberculosis $(65 \%)$ was the most common opportunistic infection. (84\%) patients had CD4 count between 50-200/cub.mm, (66\%) were in stage III. ART was well tolerated, ADRs were found in $43 \%$ of patients.

Conclusions: HIV is more common in reproductive age group with males being more affected and major route of transmission of HIV infection remains heterosexual mode.

Keywords: Adverse drug reaction, Anti retroviral therapy, HIV infection

\section{INTRODUCTION}

After the first chapter opened in the horrible history of HIV infection in 1981, it now resembles a classic infectious disease, disproportionately affecting the socially and economically vulnerable and having no boundaries whatsoever. It is fourth leading cause of death in young adults all over the world. ${ }^{1}$ In 1987, first antiretroviral drug Nucleoside Reverse Transcriptase Inhibitor (NRTI), AZT (AZIDOTHYMIDINE) - Zidovudine was introduced. In 1998 three drug therapy- highly active antiretroviral therapy (HAART) shown to delay sickness and death. ${ }^{2}$
A person living with HIV/AIDS as per revised estimate in July 2007 was 2 million. In Adults (15 years or above) HIV prevalence is $0.36 \%$. Gujarat is moderately prevalent state among all states (HIV infection has reached $5 \%$ or more among high risk groups. ${ }^{3,4}$

Human immunodeficiency virus (HIV) belongs to the family of viruses called retrovirus and sub family lentiviruses. Retroviruses are single stranded RNA virus that contains the enzyme reverse transcriptase. Currently two genetically and immunological distinct HIV is recognized as HIV-1 and HIV-2. The virion consists of envelope, capsid and core. Envelope is an external 
membrane embedded with glycoprotein Gp-41. Bound to this is outer GP-120. This GP-120 binds to CD4 receptors. Capsid is the protein core that surrounds core of the virus. It is made up of protein P-18. Core is elongated dense inner mass of the virus which contains two identical single strands of viral RNA, structural proteins and enzyme reverse transcriptase. The main core protein is $\mathrm{P}-24$. The HIV I genome has genes that encode the structural proteins of the virus (GAG, ENV, POL). ${ }^{5,6}$

Most common mode of transmission of HIV infection is sexual transmission followed by transmission through blood and blood products. ${ }^{1,7}$

Diagnosis of HIV infection includes detection of Antibodies by screening test like ELISA, Dot blot assay and confirmatory test like western blot assay and detection of specific antigen by P-24 (immune complex dissociation assay) and Revrse transcriptase assay.

'HAART' refers to use of combinations of three antiretroviral agents for treatment of HIV infection. Majority of treatment naive individuals are treated with three types of combination regimens: NNRTI- Nonnucleoside Reverse Transcriptase Inhibitor based (1NNRTI + 2 NRTI), PI -Protease Inhibitor based (Unboosted/boosted PI + 2 NRTI), and triple NRTINucleoside Reverse Transcriptase Inhibitor based regimens. Adequate treatment of Opportunistic infections with appropriate antimicrobial therapy and stabilizing patients is crucial before initiating ART. $3,6,8$

Drugs are double edged weapons. Drugs, no matter how safe and efficacious, are always coupled with inescapable risk of adverse reactions. Thus, drug safety assessment should be considered as an integral part of day to day clinical practice. Monitoring of ADRs is more important in case of chronic ailments such as HIV infection where Polytherapy is common and requires long term therapy predisposing to adverse drug events. ${ }^{9}$

\section{Objectives}

- To study clinical profile of HIV positive patients attending A.R.T. centre of a tertiary care hospital.

- To study responsible risk factors for HIV infection.

- To study various opportunistic infections among HIV positive patients.

- To study correlation between opportunistic infections and CD4 T lymphocytes count.

- To study tolerance and adherence of ART among HIV positive patients.

\section{METHODS}

There were 100 HIV positive patients attending ART centre of Guru Gobind Government hospital, Jamnagar, Saurastra, Gujarat were included in study.
It was prospective and observational study. Duration of the study was 12 Months (October 2010-September 2011). 100 HIV positive Patients, attending to ART centre of our hospital, over a period of 12 months.

\section{Inclusion criteria}

- A Patient of >12 years of age group of any sex, with HIV positive status as per ELISA test, attending to ART Centre of our hospital

- A patient who gives informed consent willfully to take part in study.

\section{Exclusion criteria}

- A Patient $\leq 12$ years of age.

- A Patient who doesn't give informed consent willfully to take part in study.

- A Patient who attends A.R.T Centre but doesn't follow the management only in A.R.T Centre of our hospital.

For each patient, detailed clinical history was noted, regarding duration and severity of symptoms of HIV infection. They were also asked about the symptoms pertaining to opportunistic infections like pulmonary koch's, chronic cough, oral candidiasis etc. Detailed physical examination was carried out in all patients looking especially for clinical evidence of associated opportunistic infections.

History was taken with special emphasis on past history of major surgery, blood transfusion, genital ulcer, multiple sexual partners, drug abuse, marital history, family history, personal history, obstetric/ gynaecological history and occupational exposure.

Routine hematological investigations in form of CBC; biochemical investigations in form of Renal and Liver function test, bacteriological investigations in form of body fluid routine and microscopy examination and radiological investigations in form of chest $\mathrm{x}$-ray were recorded from case in all patients. Serological investigation in form of S.VDRL, S.HbsAg were recorded in all patients. CD4 cell count was recorded in all patients as per NACO guideline. Patients were also studied for tolerance and adherence of ART.

\section{RESULTS}

There were $100 \mathrm{HIV}$ positive patients were analyzed to derive the following results.

Maximum number of cases of HIV infected persons belonged to age group 30-49 years (75\%) followed by $15-$ 29 years $(20 \%)$, that is depicted in (Figure 1).

Analysis of sex distribution showed that $75 \%$ were male and $25 \%$ were female with ratio of $3: 1$, that is depicted in 
(Figure 2). We observed $58 \%$ rural and $42 \%$ urban residence distribution pattern among HIV patients. In observation of marietal status, $84 \%$ were married (Males: 61 and females: 23), 16\% were unmarried (males: 14 and females: 2), none of them were divorced, separated or widow. Educational status analysis showed that $56 \%$ of patients were illiterate followed by primary $(24 \%)$ and secondary $(16 \%)$ schooling.

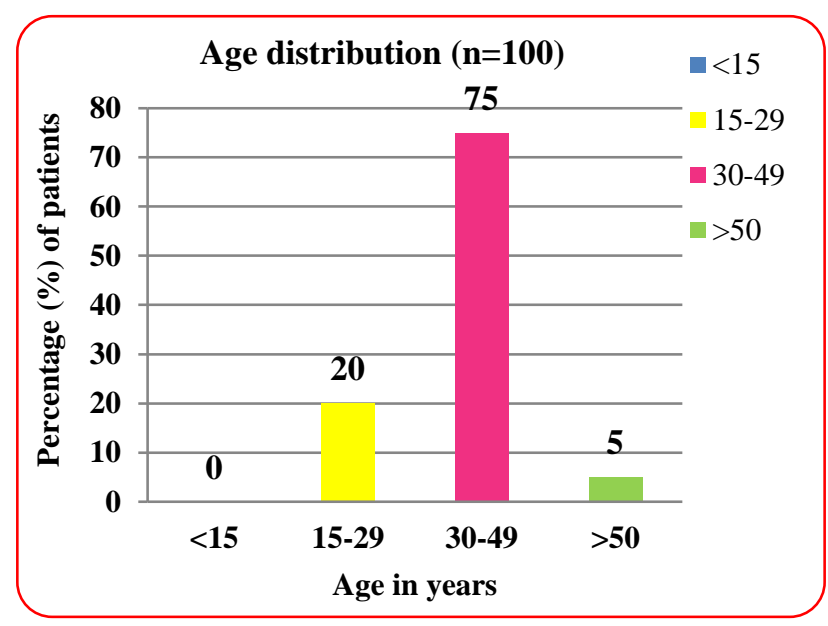

Figure 1: Age distribution $(\mathrm{n}=\mathbf{1 0 0})$.

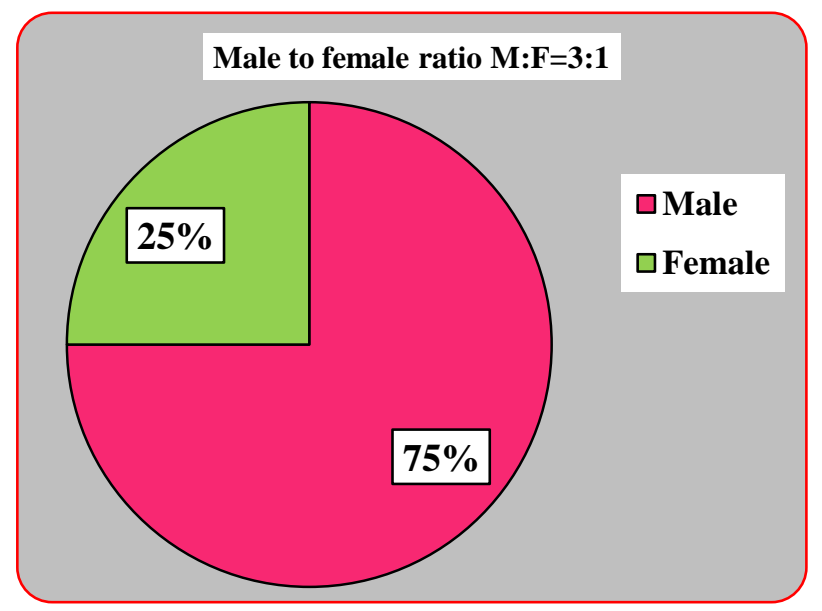

Figure 2: Sex distribution $(n=100)$.

Majority of the patients were labourer (28\%) followed by unemployed, driver, service worker being 19\%, 14\%, 12\% respectively. $57 \%$ of patients were having addiction. Majority of the patients $(43.08 \%)$ were addicted to tobacco, followed by smoking and alcohol being $35.07 \%$, $21.05 \%$ respectively. None of them were I.V / I.M drug user. Most common route of transmission was Sexual (79\%) followed by unknown and blood transfusion route being $18 \%, 03 \%$ respectively. Sexual promiscuity analysis showed that $97.46 \%$ of patients were heterosexual and $2.54 \%$ of patients were homosexual. $81.01 \%$ of patients were having two partners and $15.18 \%$ were having 1 partner. In majority of patients, $(59.5 \%)$ were having duration of sexual exposure $<5$ years. Most common symptom was weight loss in $(62 \%)$ of patients - out of them, $40.32 \%$ patients were having significant weight loss followed by fever, cough, oral candidiasis and diarrhoea being $58 \%, 50 \%, 24 \%$ and $22 \%$ respectively that is depicted in (Figure 3).

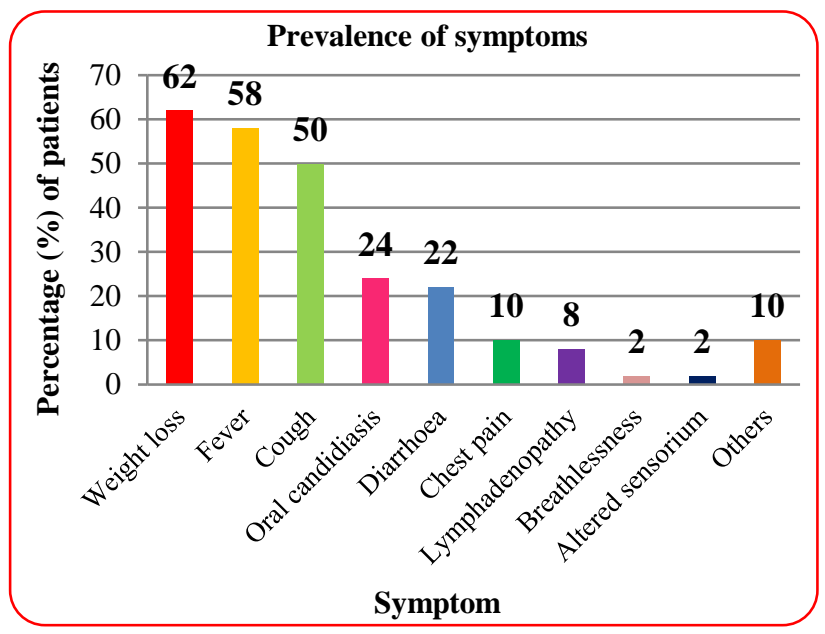

Figure 3: Prevalence of symptoms $(n=100)$.

Most common opportunistic infection was pulmonary tuberculosis (47\%), followed by oral candidiasis and extra pulmonary tuberculosis being $24 \%$ and $18 \%$ respectively, that is shown in (Table 1). Out of 47 patients of pulmonary tuberculosis, 28 patients $(59.57 \%)$ had sputum smear positive and $19(40.43 \%)$ were negative whereas $30(63.80 \%)$ were having consolidation in their chest x-ray. In extrapulmonary $\mathrm{TB}$, out of 18 patients, $8(44.5 \%)$ patients were having pleural effusion and $8(44.5 \%)$ were having lymphadenitis. Correlation of Opportunistic infections with mean CD4 count is depicted in (Figure 4).

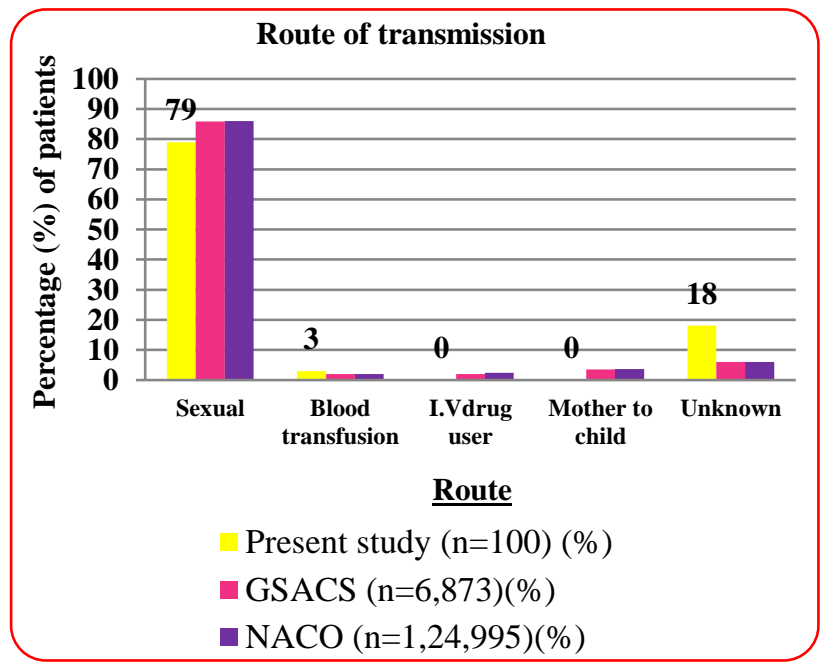

Figure 4: Route of transmission $(n=100)$.

In general examination finding, Pallor was the most common with 54 (54\%) patients. Skin lesions were found in $17 \%$ patients while icterus, clubbing and genital ulcer were found in $08 \%, 15 \%$ and $5 \%$ respectively. None of them were having cyanosis. On examination of oral cavity 
24 patient were found to have thrush while one patient was having leukoplakia. All patients $(100 \%)$ were infected with HIV TYPE I Virus. CD4 count in 100 seropositive HIV infected patients is depicted in (Table 2).

Table 1: Opportunistic infections in 100 seropositive HIV infected patients.

\begin{tabular}{|ll|}
\hline Opportunistic infection & $\begin{array}{l}\text { No. of patients } \\
\text { (Percentage \%) }\end{array}$ \\
\hline Pulmonary TB & $47(47)$ \\
\hline Extra pulmonary TB & $18(18)$ \\
\hline Oral candidiasis & $24(24)$ \\
\hline P. Jeroveci pneumonia & $02(2)$ \\
\hline Cryptococcal meningitis & $01(1)$ \\
\hline Toxoplasmosis & - \\
\hline Others & $03(3)$ \\
\hline
\end{tabular}

Table 2: CD4 count in 100 seropositive HIV infected patients.

\begin{tabular}{|ll|}
\hline CD4 count & No. of patients (Percentage \%) \\
\hline$<50$ & $01(01)$ \\
\hline $50-200$ & $84(84)$ \\
\hline $201-350$ & $15(15)$ \\
\hline$>351$ & $00(00)$ \\
\hline Total & 100 \\
\hline
\end{tabular}

Among analysis of associated STD and infectious hepatitis, $5 \%$ patients were having viral hepatitis B and $1 \%$ patient was having syphilis and positive for VDRL test. Staging of HIV infected patients, majority, 66 patients $(66 \%)$ belonged to stage III followed by 21 patients belonged to stage IV (21\%), 10 patients belonged to stage I $(10 \%)$ and 03 patients in stage II (3\%).

In Hemoglobin assessment of 100 patients, $60 \%$ of patients were having mild anaemia, $17 \%$ were having moderate and $5 \%$ patients were having severe anaemia. Out of 84 married patients 19 patients had their spouse affected and 10 patients had their children affected.

Majority (45\%) of patients had hospitalization once since their diagnosis, $34 \%$ patients had hospitalization twice, $12 \%$ patients did not have hospitalization and $9 \%$ patients had hospitalization $\geq 3$ after diagnosis. In all HIV positive patients, adherence to ART were noted and ART was well tolerared, ADRs were found in $43 \%$ of patients.

\section{DISCUSSION}

In age analysis, maximum cases of HIV infected persons belong to age group between 30-49 years followed by 15 29 years, though our data is pooled as compare to community-based survey in GSACS and NACO, it is nearly comparable to it. ${ }^{1,10}$ Maximum cases of HIV infected persons were in age group between 15-49 years, suggest HIV is more common in productive age groups.
In present study male patients were $75 \%$ and female patients were $25 \%$, which is comparable to GSACS having, $71.2 \%$ of male patients and $28.8 \%$ of female patients and NACO having male patients $70.7 \%$ and female patients $29.3 \% .^{1,10}$ It shows males are more affected than females. Patients were predominantly from the rural areas, that is comparable with study conducted by Becker ML et al, suggesting the role of poor health awareness and utilization of health services in the rural areas. ${ }^{11}$ Majority of the patients in both the studies fall into the married category, suggesting marriage as a major risk factor into the propagation of the HIV infection. Majority of the patients in both the studies seem to be illiterate implying the major role of illiteracy in spreading HIV infection.

Tobacco addiction was most common followed by smoking and alcohol. The difference was because of rampant tobacco habits in Saurashtra region of Gujarat with poor prevalence of IV/IM drug abuse which are more in north eastern states of India.

Occupation wise labourers formed a major part (28\%) in present study comparable with study by Becker ML et al. ${ }^{11}$ Incidence was high in drivers and low in unemployed in the present study as compared to Becker ML et al. ${ }^{11}$ This is because of frequently unprotected sexual practice by the labourers and drivers during their frequent outside travelling.

In present study most, common route of transmission was sexual $(79 \%)$ which is comparable to data of GSACS ${ }^{10}$ and NACO, that is depicted in (Figure 5). ${ }^{1}$

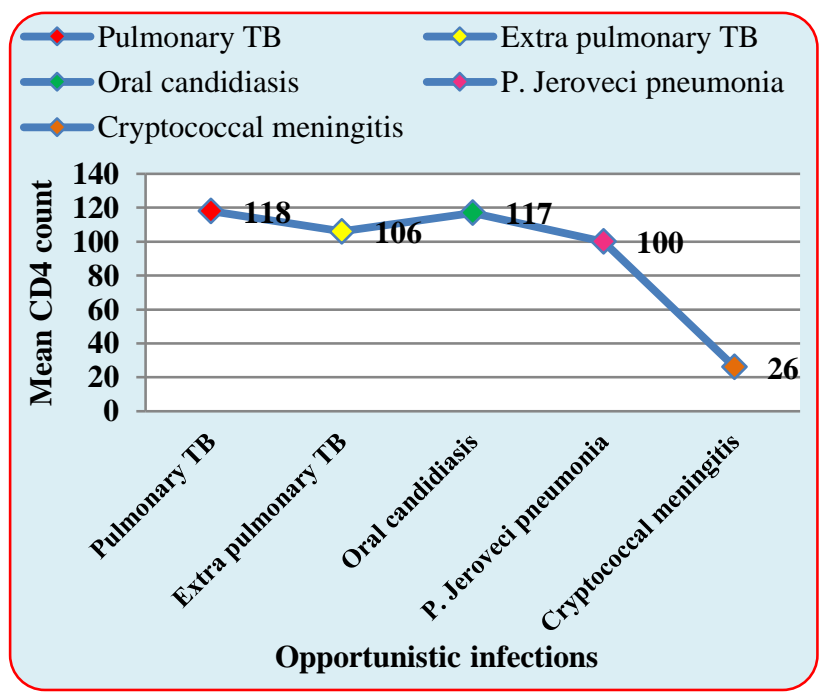

Figure 5: Correlation of Opportunistic infections with mean CD4 count $(n=100)$.

It seems that heterosexual mode is still the predominant mode of spread of HIV infection in India. Sexual exposure with two partners is still the dominant mode of spread and with duration $<5$ years in both the studies. 
In present study most common symptom was weight loss in HIV positive patients followed by fever and cough which is comparable to study of GSACS. ${ }^{10}$

Authors have observed that commonest opportunistic infection among HIV infected patient was pulmonary tuberculosis followed by oral candidiasis and extra pulmonary tuberculosis which is comparable to that of Mishra study and N. Kumarasamy et al, study. ${ }^{12,13}$ Authors have observed very little percentage of patients with $\mathrm{P}$. jeroveci pneumonia, cryptococcal meningitis, toxoplasmosis, cryptosporidium diarrhoea and CMV retinitis. Mean CD4 count for particular opportunistic infection is little lower than N. Kumarasamy et al, study, they may be related to delay in presentation of patients at our centre. ${ }^{13}$ ADR (Tolerance to ART) in this study was comparable to swiss study. ${ }^{14}$

\section{CONCLUSION}

As per present study, HIV was more common in reproductive age group with males being more affected. HIV was more prevalent among rural and illiterate population and in labourers. Major route of transmission of HIV infection remained heterosexual mode. Weight loss followed by fever were most common symptoms. Pulmonary tuberculosis was the most common opportunistic infection with mean CD4 count of 118 . Majority of the patients were in stage III.

\section{ACKNOWLEDGEMENTS}

Authors are thankful to all staff members of "ART centre", Guru Gobind Government Hospital, Jamnagar, and Dr. Manish N Mehta (Professor and Head of Department, Medicine, GGG hospital, Jamnagar) for his kind cooperation, guidance and support for successful completion of study. Authors are also grateful to their patients for their cooperation in this study.

Funding: No funding sources

Conflict of interest: None declared

Ethical approval: The study was approved by the Institutional Ethics Committee

\section{REFERENCES}

1. Training Module of National AIDS Control organization; 2006:28-46. Available at: naco.gov.in/sti-training-modules. Last accessed on 29 Sep 2011.

2. Post Graduate Medicine Volume 16th AIDS Epidemics in India Present and Future. 467. Available at: https://www.ncbi.nlm.nih.gov. Last accessed on 29 Sep 2011.

3. Clinford HL. Human Immunology Virus Disease (AIDS and Related Disorders). In: Anthony SF, Dennis LK, Dan LL, Braunwald E, Stephen LH, Larry $\mathrm{J}$, et al, editors. Harrison's Principles of Internal Medicine. $18^{\text {th }}$ Ed. New Delhi: The McGraw-Hill; 2011:1506-1587.

4. Monthly update on AIDS, NACO; 2006. Available at: naco.gov.in/documents/national-bss-2006. Last accessed on 29 Sep 2011.

5. Chacko S, John TJ, Babu PG, Jacob M, Kaur A, Mathai D. Clinical profile of AIDS in India: a review of 61 cases. The J of the Associ of Phys of Indi. 1995 Aug;43(8):535-8.

6. Gadkuri DA. Human immunodeficiency virus. In: Y P Munjal ed. API Text book of Medicine. $8^{\text {th }}$ Ed. New Delhi: JPB; 2008:167-187.

7. Specialist Training Reference Module of National AIDS Control Society; 2002:25-27. Available at: www.nacoonline.org. Last accessed on 29 Sep 2011.

8. DeJesus E, Herrera G, Teofilo E, Gerstoft J, Buendia $\mathrm{CB}$, Brand JD, et al. Abacavir versus zidovudine combined with lamivudine and efavirenz, for the treatment of antiretroviral-naive HIV-infected adults. Clinical Infectious Diseases. 2004 Oct 1;39(7):103846.

9. Ahmad SR. Adverse drug event monitoring at the food and drug administration. J Gen Intern Med. 2003;18:57-60.

10. Gujarat State AIDS control Society. Available at: www.gsacsonline.com. Last accessed on 29 Sep 2011.

11. Becker ML, Ramesh BM, Washington RG, Halli S, Blanchard JF, Moses S. Prevalence and determinants of HIV infection in South India: a heterogeneous, rural epidemic. Aids. 2007 Mar 30;21(6):739-47.

12. Mishra SN, Sengupta D, Satpathy SK. Recent trends in opportunistic infections, Southeast Asian J Trop Med Public Health 1998;29:373-6.

13. Kumarasamy N. Clinical profile of HIV in India. Indian J Med Res. April 2005; 121:377-94.

14. Swiss Health Authorities; evaluation the prevalence of adverse events in 1160 patients who were receiving ART, Swiss HIV cohort Study; July 2002.

Cite this article as: Doshi TM, Mistry RA, Mehta MN. Clinical profile of HIV positive patients attending ART centre of a tertiary care hospital. Int J Basic Clin Pharmacol 2018;7:1542-6. 